\title{
Frequency of meningitis in neonates having late onset sepsis.
}

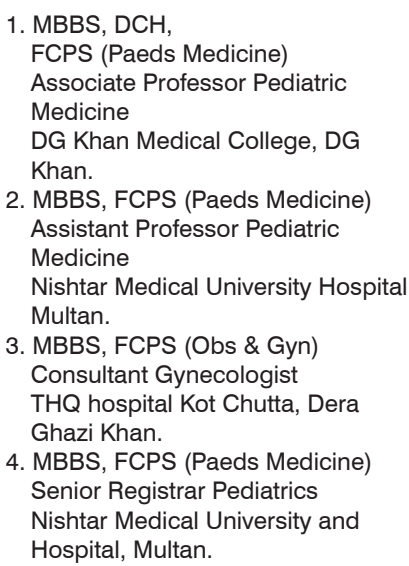

2. MBBS, FCPS (Paeds Medicine) Assistant Professor Pediatric Medicine

Nishtar Medical University Hospital Multan.

3. MBBS, FCPS (Obs \& Gyn) Consultant Gynecologist THQ hospital Kot Chutta, Dera Ghazi Khan.

4. MBBS, FCPS (Paeds Medicine) Senior Registrar Pediatrics Nishtar Medical University and Hospital, Multan.

Correspondence Address:

Dr. Shakeel Ahmad

Associate Professor of Pediatric Medicine

DG Khan Medical College, DG Khan. dr_leghari190@yahoo.com

Article received on:

28/02/2020

Accepted for publication:

24/04/2020

\section{INTRODUCTION}

Despite better hygienic standards and access to healthcare facilities in the recent decades, neonatal infections are still known be a major cause of morbidity as well as mortality among newborns around the globe. ${ }^{1}$ Majority of the researchers reporting incidence and etiology surrounding neonatal sepsis along with meningitis are from developed countries while limited work is noticed from developing countries where overall burden of these disease are immense. ${ }^{2}$ Incidence of neonatal meningitis from developed countries have been reported around 0.3/1000 live births while these figures soar up to $0.08-6.1$ per 1000 live births in developing countries, while mortality ranges between $40-58 \%{ }^{3}$

Sepsis is labeled as early-onset sepsis (EOS) or LOS. LOS is described as systemic infection occurring beyond $1^{\text {st }} 72$ hours following birth. ${ }^{4}$ Any newborn with bacterial sepsis is also at risk of meningitis. ${ }^{5}$ Meningitis is frequently found in LOS cases in comparison to EOS while it is also found that LOS linked meningitis is usually presenting with symptoms. ${ }^{4}$

Reported incidence of meningitis among neonatal sepsis ranges between $0.3-3 \%$ while LOS is noted to have a significant association with the presence of meningitis, found in $3-30 \%$ of the cases. ${ }^{6}$ In all neonates having LOS, lumber puncture (LP) is commonly performed when the clinical status of the individual stabilizes. ${ }^{7}$

Prevalence of meningitis in LOS was seen as $16 \%$ by Roshi $B$ et al from India. ${ }^{6}$ In another study, it was reported that, meningitis in LOS was $39.5 \%{ }^{8}$ In another study, meningitis in LOS was $61.1 \% .{ }^{9}$ Researches done to look for frequency of meningitis in LOS have been found to have variability while very limited work is seen at local level in this regard. The findings of this study were thought to help us in better understanding the burden of meningitis among LOS in our 
population while it will also open doors for newer research protocols looking at priorities for the management of affected patients. The current study was aimed to determine the frequency of meningitis in children having LOS.

\section{MATERIAL \& METHODS}

The descriptive case series study was conducted at the Department of Pediatrics Medicine, Nishter Medical University Multan and DHQ Teaching Hospital, Dera Ghazi Khan from July to December 2019. Ethical and research committee of the respective institutes approved the study. Informed consent was sought from the parents/ guardians of all study participants.

The sample size of 206 is estimated by using 95\% confidence level, 5\% margin of error with an expected percentage of Meningitis i.e. $16 \%$ in patients with LOS. ${ }^{6}$

Adopting non-probability consecutive sampling technique, a total of 206 neonates (103 from each center) of both gender, older than 72 hours, admitted and diagnosed with sepsis were enrolled. Sepsis screening included (TLC $<5000$ / $\mathrm{mm}^{3}$ or $>20000 / \mathrm{mm}^{3}$, absolute Leucocyte count $<1800 / \mathrm{mm}^{3}$, CRP $>1 \mathrm{mg} / \mathrm{dl}$, micro ESR $>15 \mathrm{~mm}$, IT ratio $>0.2$, platelet count pf $<15000 / \mathrm{mm}^{3}$ ), while presence of any 2 of these 6 parameters was considered as the presence of sepsis. ${ }^{10}$

Neonates with spina bifida (e.g. meningocoele, myelomeningocoele, lipomeningocoele), anencephaly, other neural tube defects, or with gross congenital anomalies making lumber puncture practically impossible (meningocele, meningomyelocele) were excluded.

Demographic information of all study participants like age and gender were noted. Cases having provisional diagnosis of sepsis underwent LP and CSF were sent to institutional laboratory for cytology and biochemistry. Meningitis was labeled in a neonate if his/her CSF contains > 30 leukocytes $/ \mathrm{mm},{ }^{3}$ and any one of these two: protein $>200 \mathrm{mg} / \mathrm{dl}$ or sugar $<40 \mathrm{mg} / \mathrm{dl}^{8}{ }^{8}$

All the data was collected through a pre-designed proforma and analyzed using SPSS version 23.0. Frequencies and percentages were expressed for qualitative variables like gender and meningitis. Quantitative variables like age were expressed by Mean \pm S.D. Data was stratified for age, gender, weight and gestation to deal with effect modifiers. For post stratification, chi-square test was applied to see the significance. P-value $\leq 0.05$ was considered significant.

\section{RESULTS}

Out of a total of 206 neonates having LOS, 111 (53.9\%) were male and 95 (46.1\%) female. Overall, mean age was noted to be $11.28+5.4$ days whereas majority of the neonates, 73 (35.4\%) were aged 3 to 7 days, followed by 13 to 17 days 44 (21.4\%) and 39 (18.9\%) 8 to 12 days. Overall, mean weight was found to be $2.68+0.51$ $\mathrm{kg}$. A total of 84 (40.8\%) neonates were preterm.

Figure-1 shows that meningitis was found in $44(21.4 \%)$ neonates. When neonates having meningitis were compared with those having no meningitis, low body weight and preterms were noted to have significant associations ( $p$ value $<$ 0.05 ) with meningitis while gender and age were not found to have any significant association as shown in Table-l.

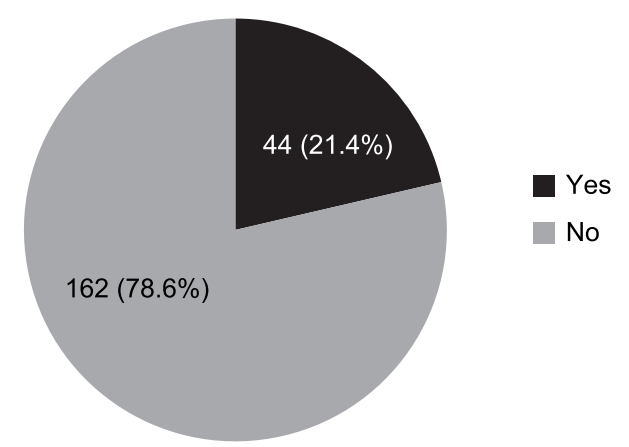

Figure-1. Frequency of meningitis in neonatal with late-onset sepsis.

\section{DISCUSSION}

LOS is usually presented after 72 hours of age and commonly along with septicemia, pneumonia or meningitis. In developing countries, neonatal meningitis has been noted to impact $33-48 \%$ mortality rates while among developed countries, these figures are around $10 \% .{ }^{11}$ 


\begin{tabular}{|c|c|c|c|c|}
\hline \multicolumn{2}{|c|}{ Study Variables } & Meningitis $(n=44)$ & No Meningitis $(n=162)$ & P-Value \\
\hline \multirow{2}{*}{ Gender } & Male & $23(52.3 \%)$ & $88(54.3 \%)$ & \multirow{2}{*}{0.8090} \\
\hline & Female & $21(47.7 \%)$ & $74(45.7 \%)$ & \\
\hline \multirow{5}{*}{$\begin{array}{l}\text { Age of Presentation } \\
\text { (days) }\end{array}$} & $3-7$ & $18(40.9 \%)$ & 55 (34.0\%) & \multirow{5}{*}{0.5963} \\
\hline & $8-12$ & $6(13.6 \%)$ & $33(20.4 \%)$ & \\
\hline & $13-17$ & $7(15.9 \%)$ & $37(22.8 \%)$ & \\
\hline & $18-22$ & $8(18.2 \%)$ & $24(14.8 \%)$ & \\
\hline & $23-27$ & $5(11.4 \%)$ & $13(8.0 \%)$ & \\
\hline \multirow{3}{*}{ Weight (kg) } & $<1.5$ & $3(6.8 \%)$ & $19(11.7 \%)$ & \multirow{3}{*}{0.0005} \\
\hline & $1.5-2.5$ & $26(59.1 \%)$ & $45(27.8 \%)$ & \\
\hline & $>2.5$ & $15(34.1 \%)$ & $98(60.5 \%)$ & \\
\hline \multirow{2}{*}{ Gestational Age } & Pre-Term & $24(54.5 \%)$ & $60(37.0 \%)$ & \multirow{2}{*}{0.0361} \\
\hline & Term & $20(45.5 \%)$ & $102(63.0 \%)$ & \\
\hline
\end{tabular}

Table-I. Comparison of LOS cases with and without meningitis with regards to study variables.

In the present study, it was noted that majority, $53.9 \%$ of the neonates were male. A recent study from Mumbai India ${ }^{12}$ noted $62.01 \%$ neonates with LOS to be male. A local study from Gangaram Hospital, Lahore ${ }^{8}$, noted $53.7 \%$ of the neonates having LOS to be male which is very similar to current observation. It has been observed that males have 2-5 fold more chances of developing septicemia in comparison to females while our result were in accordance to various other findings. ${ }^{13-15}$

Overall, mean age was noted to be $11.28+5.4$ days whereas majority of the neonates, 73 (35.4\%) were aged 3 to 7 days, followed by 13 to 17 days $44(21.4 \%)$ and $39(18.9 \%)$ between 8 to 12 days. Our findings with regards to age of the neonates were very similar to Jha AK et al from India $^{13}$ where majority, $46 \%$ of the neonates with LOS were between 3 to 7 days of age. Bhagat $\mathrm{R}$ and Colleagues ${ }^{16}$ also witnessed $46.1 \%$ of the neonates with LOS to be between 3 to 7 days of age.

We noted meningitis was found in 44 (21.4\%) neonates having LOS in the current work. In a prospective trial spanning 1 year, Kaul $\mathrm{V}$ from India ${ }^{5}$ found $23 \%$ of the cases with LOS to have meningitis which is quite close to those figures which we found in the present study. A local study from Gangaram Hospital, Lahore ${ }^{8}$ noted nearly $40 \%$ of the neonates with LOS to have meningitis which is a bit higher which we found in this study.
Researchers from Kenya ${ }^{17}$, Brazil ${ }^{18}$ and other parts of Asia ${ }^{19}$ have found frequency of meningitis ranging between $17-18 \%$ which is close to which we found. Minor differences regarding the presence of meningitis in LOS could be because of difference in factors related to epidemiology and geography in community acquired infection in LOS.

In the present study, low body weight and preterm newborns were noted to have significant associations ( $p$ value $<0.05$ ) with meningitis. It has been found earlier as well that meningitis was present in $63 \%$ of the low body weight neonates having LOS and $62 \%$ of the preterm neonates were also having meningitis which again emphasizes which was found in the present work. ${ }^{16}$ Higher frequency of meningitis among low birth weight and preterm neonates have also been described by other researches as well. ${ }^{20,21}$ Umait $S$ et al from India ${ }^{12}$ also noted among neonates having LOS with meningitis, $73 \%$ and $77 \%$ were preterm and had low body weight which is in accordance to current findings.

Frequency of meningitis found in the present research is somewhat similar to the findings of the other researcher. Early recognition of meningitis should be made while all cases of LOS should be screened thoroughly for the presence of meningitis which could enable us to devise strategies and approaches to reduce the burden of LOS. 
Involvement of multiple centers as well as confirmed cases of LOS are some of the strengths of this study. Our study also has some limitations. We did not evaluate breastfeeding trends among study participants. We could not note etiological factors or aspects related to management and outcome in this research which would have further given us valuable insights about the current practices at our settings.

\section{CONCLUSION}

Frequency of meningitis in neonates with LOS was high. Low body weight and preterm neonates having LOS were found to have significant association with the presence of meningitis.

\section{Copyright@ 24 Apr, 2020.}

\section{REFERENCES}

1. Bentlin MR, de Souza Rugolo LM. Late-onset sepsis: Epidemiology, evaluation, and outcome. Neo Reviews. 2010; 11(8):426-35.

2. Simonsen KA, Anderson-Berry AL, Delair SF, Davies HD. Late-Onset Neonatal Sepsis. Clin Microbiol Rev. 2014; $27(1): 21-47$.

3. Nesher L, Hadi CM, Salazar L, Wootton SH, Garey $\mathrm{KW}$, Lasco $\mathrm{T}$, et al. Epidemiology of meningitis with a negative CSF Gram stain: Under-utilization of available diagnostic tests. Epidemiol \& Infec. 2016; 144(1):189-97.

4. Aleem S, Greenberg RG. When to Include a Lumbar Puncture in the Evaluation for Neonatal Sepsis. Neo Reviews 2019; 20(3):e124-e134.

5. Kaul V, Harish R, Ganjoo S, Mahajan B, Raina SK, Koul D. Importance of obtaining lumbar puncture in neonates with late onset septicemia a hospital based observational study from North-West India. J Clinic Neonat. 2013; 2(2):83-7.

6. Roshi B, Sheikh QH, Imran AG, Shabir AW. Incidence of meningitis in late onset sepsis. Int $\mathrm{J}$ Contemp Pediatr. 2015; 2(2):96-102.

7. Stoll BJ, Hansen NI, SÃinchez PJ, Faix RG, Poindexter $B B$, Van Meurs KP, et al. Early onset neonatal sepsis: The burden of group B streptococcal and E. coli disease continues. Pediatrics. 2011; 127(5):817-26.

8. Saleem S, Akbar N, Anwar A, Mehmood R. Meningitis in Neonatal Late Onset Sepsis. APMC 2015; 9(3):140144.
9. Arora V, Sharma LM, Jangid D, Choudhary V, Bairwa RP, Singla S. Meningitis in late onset sepsis. Int $J$ Contemp Pediatr 2017; 4:1056-60.

10. Tiwari $A$, Dewan $M$, Rattan $A$. Laboratory investigations for neonatal sepsis. Acta Scientific Microbiology Special Issue (2019):1:42-46.

11. Furyk JS, Swann O, Molyneux E. Systematic review: Neonatal meningitis in the developing world. Tropical Medicine and International Health 2011; 16(6):672-9.

12. Umate S, Garg BD, Kabra NS. Incidence of meningitis in neonates with late-onset sepsis at a Tertiary Care Center in Western India: An observational study. J Clin Neonatol 2019; 8:67-70.

13. Jha AK, Jaiswal AK. Assessment of occurrence of the meningitis in neonates with late onset sepsis admitted to Patna Medical College and Hospital, Patna. International Journal of Medical and Health Research 2019; 5(4):122-5.

14. Tallur SS, Kasturi AV, Nadgir SD, Krishna BV. Clinicobacteriological study of neonatal septicemia in Hubli. Indian J Pediatr. 2000; 67:169-74.

15. Aletayeb SM, Khosravi AD, Dehdashtian M, Kompani F, Mortazavi SM, Aramesh MR. Identification of bacterial agents and antimicrobial susceptibility of neonatal sepsis: A 54-month study in a tertiary hospital. African J Microbiol Res. 2011; 5:528-31.

16. Bhagat $R$, Hussain $S Q$, Gattoo IA, Wani SA. Incidence of meningitis in late onset sepsis. Int $\mathrm{J}$ Contemp Pediatr 2015; 2:96-102.

17. Laving AM, Musoke RN, Wasunna AO, Revathi G. Neonatal bacterial meningitis at the newborn unit of Kenyatta National Hospital. East Afr Med J 2003; 80:456-62.

18. da Silva LP, Cavalheiro LG, Queirós F, Nova CV, Lucena $R$. Prevalence of newborn bacterial meningitis and sepsis during the pregnancy period for public health care system participants in Salvador, Bahia, Brazil. Braz J Infect Dis 2007; 11:272-6.

19. Tiskumara R, Fakharee SH, Liu CQ, Nuntnarumit P, Lui $\mathrm{KM}$, Hammoud $\mathrm{M}$, et al. Neonatal infections in Asia. Arch Dis Child Fetal Neonatal Ed 2009; 94:F144-8.

20. Longe AC, Omene JA, Okolo AA. Neonatal meningitis in Nigerian infants. Acta Pediatr Scand. 1984; 73:47781.

21. Moreno MT, Vargas $S$, Poveda $R$, Sáez-Llorens $X$. Neonatal sepsis and meningitis in a developing Latin American country. Pediatr Infect Dis J. 1994; 13:51620. 


\section{AUTHORSHIP AND CONTRIBUTION DECLARATION}

\begin{tabular}{|c|c|c|c|}
\hline Sr. \# & Author(s) Full Name & Contribution to the paper & Author(s) Signature \\
\hline 1 & Shakeel Ahmad & Study idea, Design, Supervision. & Trikeel. \\
\hline 2 & Nusrat Hussain & $\begin{array}{l}\text { Data collection, Literature review, } \\
\text { Proof reading. }\end{array}$ & Ausnat \\
\hline 3 & Tayyaba Rafique & $\begin{array}{l}\text { Data analysis, Discussion, } \\
\text { Drafting. }\end{array}$ & Tayyabs. \\
\hline 4 & Rabia Saleem & $\begin{array}{l}\text { Data collection, Data } \\
\text { interpretation. }\end{array}$ & Punidguenglar \\
\hline
\end{tabular}

